\title{
Constructal design of combined microchannel and micro pin fins for electronic cooling O.O. Adewumi ${ }^{\mathrm{a}}$, T. Bello-Ochende ${ }^{1 \mathrm{~b}}$ and J.P. Meyer $^{\mathrm{a}}$
}

${ }^{a}$ Department of Mechanical and Aeronautical Engineering, University of Pretoria, Pretoria Private Bag X20, Hatfield, 0028, South Africa.

${ }^{\mathbf{b}}$ Department of Mechanical Engineering, University of Cape Town, Cape Town Private Bag X3, Rondebosch, 7701, South Africa.

\begin{abstract}
This paper presents a three-dimensional numerical study of steady, laminar, incompressible flow and forced convection heat transfer through a microchannel heat sink with micro pin fin inserts for both fixed and variable axial lengths. The objective of the study was to optimise the geometric configuration of an integrated microchannel and micro pin fins for different solid volumes so that the peak temperature in the configuration was minimised. The effect of the micro pin fins on the optimised microchannel was also investigated. The geometric optimisation of the integrated microchannel and micro pin fin was carried out using a computational fluid dynamics (CFD) code with a goal-driven optimisation tool subject to global constraints. The optimisation procedure was carried out in two steps. Firstly, the microchannel configuration was optimised without the micro pin fins inserted and the results were compared with similar work found in the open literature. This optimisation was carried out for both fixed and relaxed lengths. Thereafter, the integrated design of the microchannel and micro pin fins was optimised. The effect of the Bejan number on the solid volume fraction, channel aspect ratio and hydraulic diameter, pin fin aspect ratio, minimised peak temperature and maximized thermal conductance were reported.

Results showed that as the Bejan number increased, the minimised peak temperature decreased. Also, the maximum thermal conductance increased with the optimised microchannel structure with three to six rows of micro pin fin inserts. Diminishing return set in when the number of rows of micro pin fin inserts was greater than three for the fixed length but for the relaxed length, as the number of rows increased, the results improved but when it exceeded six diminishing returns set in for a fixed solid volume of $0.9 \mathrm{~mm}^{3}$. For each Bejan number used in this study, there was an optimum channel hydraulic diameter and aspect ratio, solid volume fraction and pin fin aspect ratio that satisfied the global objective.
\end{abstract}

Keywords: Forced convection; Minimised peak temperature; Channel hydraulic diameter; Channel aspect ratio; Solid volume fraction; Pin-fin aspect ratio; Bejan number; Microchannel heat sink; Micro pin fin; Fixed length; Relaxed length.

\footnotetext{
${ }^{1}$ Corresponding author:

E-mail: tunde.bello-ochende@uct.ac.za

Phone: +27 (0) 216503673

Fax: +27 (0) 216503240
} 


\section{Nomenclature}

\begin{tabular}{|c|c|}
\hline$A$ & Area $\left(m^{2}\right)$ \\
\hline$B e$ & Bejan number \\
\hline$C$ & Global thermal conductance \\
\hline$C_{p}$ & Heat capacity $(\mathrm{J} / \mathrm{K})$ \\
\hline$D_{h}$ & Channel hydraulic diameter $(\mathrm{m})$ \\
\hline$D_{f}$ & Pin-fin diameter $(\mathrm{m})$ \\
\hline$H_{c}$ & Channel height (m) \\
\hline$H_{f}$ & Pin-fin height (m) \\
\hline$k_{s}$ & Thermal conductivity of solid wall (W/mK) \\
\hline$k_{f}$ & Thermal conductivity of fluid (W/mK) \\
\hline$M$ & Height of computational volume (m) \\
\hline$N$ & Length (m) \\
\hline$P$ & Pressure $(\mathrm{Pa})$ \\
\hline$q$ & Heat transfer rate $(\mathrm{W})$ \\
\hline$q^{\prime \prime}$ & Heat flux $\left(\mathrm{W} / \mathrm{m}^{2}\right)$ \\
\hline$R_{t h}$ & Thermal resistance ( K/W $),\left(R_{t h}=\frac{T_{f i n}-T_{a i r}}{q}\right)$ \\
\hline$s$ & Pin-fin spacing (m) \\
\hline$T$ & Temperature $\left({ }^{\circ} \mathrm{C}\right)$ \\
\hline$t_{1}$ & Half-width thickness of vertical solid (m) \\
\hline$t_{2}$ & Channel base thickness (m) \\
\hline$t_{3}$ & Channel base to height distance (m) \\
\hline$u, v, w$ & Velocities in the $x$-, $y$ - and $z$-directions $(\mathrm{m} / \mathrm{s})$ \\
\hline
\end{tabular}




$\begin{array}{ll}V & \text { Computational domain volume }\left(\mathrm{m}^{3}\right) \\ V_{f} & \text { Volume of micro pin-fin }\left(\mathrm{m}^{3}\right) \\ W & \text { Computational domain width }(\mathrm{m}) \\ W_{c} & \text { Channel width }(\mathrm{m}) \\ W_{t} & \text { Total width of solid volume }(\mathrm{m})\end{array}$

\section{Greek Symbols}

$\begin{array}{ll}\Delta & \text { Difference } \\ \rho & \text { Density }\left(\mathrm{kg} / \mathrm{m}^{3}\right) \\ \mu & \text { Dynamic viscosity }(\mathrm{kg} / \mathrm{m} . \mathrm{s}) \\ \alpha & \text { Thermal diffusivity }\left(\mathrm{m}^{2} / \mathrm{s}\right) \\ \phi & \text { Volume fraction }\end{array}$

\section{Subscripts}

$\begin{array}{ll}\text { atm } & \text { Atmosphere } \\ f & \text { Fluid } \\ \max & \text { Maximum } \\ \min & \text { Minimum } \\ \text { opt } & \text { Optimum } \\ \text { out } & \text { Outlet } \\ \text { solid } & \text { Solid } \\ 1-6 & \text { Number of rows of pin fins }\end{array}$

\section{Introduction}

Almost all literature acknowledges that the approach of utilising microchannel heat sinks to remove high heat fluxes in microelectromechanical systems (MEMS) was first presented by 
Tuckerman and Pease [1]. Since then, many analytical, experimental and numerical investigations have been carried out on microchannel and micro pin fin heat sinks especially in the area of geometric optimisation using different optimisation tools. Some of these works are mentioned below.

Knight et al. [2] used an analytical technique to optimise heat sinks with application to microchannel and their results showed 10 to $35 \%$ improvement in the thermal resistance over those presented by Tuckerman and Pease [1] and two other previous investigations. Other analytical investigations with optimisation with application to electronic cooling were carried out by Perret et al. [3] and Murakami and Mikic [4].

Numerical investigations were carried out by Ryu et al [6], [7] on microchannel heat sinks using the finite volume method incorporating an optimisation scheme which used the random search technique. Muller and Frechette [8] also used a numerical optimisation tool to optimise forced convection in microchannel heat sinks for minimum pumping power at high heat fluxes. The optimal fin configuration was found using the Newton method.

A detailed numerical simulation of the heat transfer occurring in a silicon-based microchannel heat sink with optimisation of the geometric structure using a simplified threedimensional conjugate heat transfer model (2D fluid flow and 3D heat transfer) was carried out by $\mathrm{Li}$ and Peterson $[9,10]$. Ndao et al. [11] carried out a multi-objective thermal design optimisation and comparative study of different electronic cooling technologies, which included microchannels, circular pin fins, offset strip fins and jet impingement using MATLAB's multi-objective algorithm functions to determine the optimal thermal design of each technology.

Husain and Kim [12] also carried out a numerical investigation of 3D fluid flow and heat transfer in a rectangular microchannel using water as a cooling fluid in a silicon substrate. Commercial code CFX 5.7 was used to formulate the numerical model while three surrogate models were applied to predict the optimal design point that minimises thermal resistance.

A more recent approach applied to studies carried out to investigate forced convection heat transfer in microchannel heat sinks is a geometric optimisation technique involving constraint specification. This approach is based on the constructal theory, which begins with the global objective(s) and the global constraint(s) of the flow system, and the fact that in the beginning, 
the geometry of the flow is missing [15]. This approach was also used in the geometric optimisation of pin fins [16-19].

Bello-Ochende et al. [13] and Ighalo [14] observed that in literature, in order to achieve optimal designs of microchannel heat sinks using CFD, optimisation was carried out using trial-and-error simulations. They proposed a design methodology which combined CFD with a mathematical optimisation algorithm (a leapfrog optimisation program and DYNAMIC-Q algorithm), which automated the optimisation process. Their results were compared with that obtained by Bello-Ochende et al. [15] which used the trial-and-error method. Ighalo [14] also used this method to optimize two and three rows of pin fins.

From the observation of Bello-Ochende et al. [13], this present work is aimed at optimising a rectangular microchannel heat sink embedded with micro pin fins using the goal-driven optimisation tool in the ANSYS workbench, which is an automated process. The advantage of this optimisation tool is that the geometry, meshing, simulation and the optimisation are carried out in the ANSYS workbench unlike the method previously used [13], where they had to couple the mathematical optimisation algorithm to FLUENT 6. In this work, a fixed volume constraint is applied to obtain global optima with respect to the channel aspect ratio, solid volume fraction, channel hydraulic diameter, pin-fin aspect ratio and Bejan number. The optimisation of the integrated microchannel and micro pin-fin heat sink will be based on minimising the peak temperature of the highly conductive silicon substrate into which they are inserted for fixed and variable lengths.

\section{Model description}

A physical model of a microchannel embedded inside a high-conducting solid which is the same used in the investigation carried out by Bello-Ochende et al. [13], is shown in Figure 1. Figure $2 \mathrm{a}$ and $2 \mathrm{~b}$ shows the elemental volume of the microchannel heat sink inserted with micro pin fins used as the computational domain in this study. The length $N$, height $M$ and width $W$ of the solid are fixed, which makes the volume $V$ fixed while $\mathrm{t}_{1}, \mathrm{t}_{2}, \mathrm{t}_{3}, \mathrm{H}_{\mathrm{c}}$ and $\mathrm{W}_{\mathrm{c}}$ are varied but also subject to manufacturing constraints. The solid volume fraction or porosity $\phi$ is defined as the ratio of the solid volume to the total volume of the heat sink, which is only dependent on the cross-sectional area of the heat sink as shown in Equation (1). 
$\phi=\frac{V_{\text {solid }}}{V}=\frac{A_{\text {solid }} N}{A N}=\frac{A_{\text {solid }}}{A}=\frac{M W-H_{c} W_{c}}{M W}$

The fixed global volume is defined as

$V=M W N=$ const

The manufacturing constraints are

$$
\begin{aligned}
& \frac{H_{c}}{W_{c}} \leq 20 \\
& t_{2} \geq 50 \mu \mathrm{m} \\
& M-t_{3} \geq 50 \mu \mathrm{m}
\end{aligned}
$$

The micro pin fins inserted in the optimised micro-channel are also subject to the manufacturing constraints in Equations (6) and (7).

$$
0.5 \leq \frac{H_{f}}{D_{f}} \leq 4.0
$$

$s \geq 50 \mu m$

A total fin volume constraint is applied to the micro pin fins where the volume of the cylindrical fins is constant as shown in Equation (8).

$V_{f}=V_{f 1}+V_{f 2}+\ldots \ldots \ldots+V_{f n}=$ cons $\tan t$

\subsection{Governing equations}

The present study assumes that the flow is steady and laminar. The cooling fluid, which is water, is also assumed to be incompressible with homogeneous and constant thermophysical properties. Radiation and natural convection are assumed to be negligible.

The temperature distribution within the geometry used in this study was determined by solving the conservation of mass, momentum and energy Equations (9)-(12) numerically. The governing equations solved after applying the above assumptions are,

$\nabla \cdot \vec{v}=0$

$\rho(\vec{v} \cdot \nabla \vec{v})=-\nabla P+\mu \nabla^{2} \vec{v}$ 
$\rho_{f} C_{p f}(\vec{v} \cdot \nabla T)=k_{f} \nabla^{2} T$

The energy equation for the solid regions can be written as:

$k_{s} \nabla^{2} T=0$

The heat flux between the interface of the fluid and the solid walls is coupled and its continuity between the interface of the solid and the liquid is given as:

$\left.k_{s} \frac{\partial T}{\partial n}\right|_{\text {wall }}=\left.k_{f} \frac{\partial T}{\partial n}\right|_{\text {wall }}$

\subsection{Boundary conditions}

The inlet boundary conditions

$\mathrm{p}=\mathrm{P}_{\text {in }}, \mathrm{v}=\mathrm{w}=0$

$P_{i n}=\frac{B e \alpha \mu}{V^{\frac{2}{3}}}+P_{o u t}$

where $B e$ known as Bejan number $[20,21]$ is the dimensionless pressure difference and

$\alpha=\frac{k}{\rho C_{p}}$

$\mathrm{T}=\mathrm{T}_{\mathrm{in}}$

At the outlet, the boundary condition is specified as,

$\mathrm{P}_{\mathrm{out}}=\mathrm{P}_{\mathrm{atm}}$

Symmetry boundary conditions are specified at the left and right side of the domain, that is, the normal gradient of all the variables is zero as shown in Equation (19).

$\frac{\partial T}{\partial x}=0$

A no-slip boundary condition is specified at the walls,

$\mathrm{u}=\mathrm{v}=\mathrm{w}=0$

A constant uniform heat flux $q "$ is applied at the bottom wall, 
$q^{\prime \prime}=k_{s} \frac{\partial T}{\partial y}$

The measure of performance is the dimensionless global thermal conductance which could be expressed in dimensionless form as

$C=\frac{q^{\prime \prime} N}{k_{f} \Delta T}$

where the excess temperature $\Delta \mathrm{T}$ is

$\Delta T=T_{\max }-T_{\min }$

\section{Numerical procedure, grid analysis and code validation}

The continuity, momentum and energy Equations (9)-(12) along with the boundary conditions (13)-(21) were solved numerically using a three-dimensional commercial CFD package, ANSYS 14.0 [22], which employs a finite volume method. The detail of this method is explained by Patankar [23]. The computational domain was meshed using hexagonal/wedge, tetrahedron and pyramid elements. A second-order upwind scheme was used to discretise the combined convection and diffusion terms in the momentum and energy equations and then the SIMPLE algorithm was employed to solve the coupled pressurevelocity fields in the equations.

The solution is assumed to converge when the normalised residuals of the continuity and momentum equation fall below $10^{-5}$ while that of the energy equation falls below $10^{-7}$.

The convergence criterion for the peak temperature as the quantity monitored is:

$\gamma=\left|\frac{\left(T_{\max }\right)_{i}-\left(T_{\max }\right)_{i-1}}{\left(T_{\max }\right)_{i}}\right| \leq 0.01$

where $\mathrm{i}$ is the mesh iteration index.

The mesh is more refined as $\mathrm{i}$ increases and $\mathrm{i}-1$ mesh was selected as the convergence criterion once Equation (24) was satisfied.

Table 1 shows the dimensions of the geometry used to carry out the grid refinement test as shown in Table 2 for a Bejan number, $B e=1.9 \times 10^{8}$. 
Table 1: Dimensions of the microchannel heat sink for grid refinement test

\begin{tabular}{|c|c|c|c|c|c|c|c|}
\hline $\mathbf{t}_{\mathbf{1}}$ & $\mathbf{M}-\mathbf{t}_{\mathbf{3}}$ & $\mathbf{t}_{\mathbf{3}}$ & $\mathbf{W}_{\mathbf{c}}$ & $\mathbf{H}_{\mathbf{c}}$ & $\mathbf{W}$ & $\mathbf{M}$ & $\mathbf{N}$ \\
$(\mathbf{m m})$ & $(\mathbf{m m})$ & $(\mathbf{m m})$ & $(\mathbf{m m})$ & $(\mathbf{m m})$ & $(\mathbf{m m})$ & $(\mathbf{m m})$ & $(\mathbf{m m})$ \\
\hline 0.02 & 0.21 & 0.69 & 0.06 & 0.48 & 0.1 & 0.9 & 10 \\
\hline
\end{tabular}

Table 2: Grid refinement test results

\begin{tabular}{|c|c|c|}
\hline Number of cells & $\Delta T(K)$ & $\left|\frac{(\Delta T)_{i}-(\Delta T)_{i-1}}{\Delta(T)_{i}}\right|$ \\
\hline 18458 & 14.3420 & - \\
29777 & 15.0306 & 0.0458 \\
47607 & 15.4470 & 0.0270 \\
75082 & 15.6063 & 0.0102 \\
109599 & 15.6545 & 0.0031 \\
\hline
\end{tabular}

The validation of the CFD code used was carried out by comparing the numerical results obtained using this code with the analytical results obtained from the investigation carried out by Khan et al., who analysed the performance of a cylindrical pin-fin heat sink in laminar forced convection [24]. The solution trends were in good agreement with a maximum deviation of less than $7 \%$ as shown in Fig. $3 a$ and $16 \%$ in Fig. 3b. This gives us confidence in the numerical code adopted. A grid refinement test was also carried out for the integrated microchannel with pin fins for $B e=1.9 \times 10^{8}$ as shown in Table 4. Table 3 shows the dimensions of the geometry used for the grid refinement test.

Table 3: Dimensions of the microchannel and micro pin-fin heat sink for grid refinement test

\begin{tabular}{|c|c|c|c|c|c|}
\hline $\mathbf{H}_{\mathbf{c}}(\mathbf{m m})$ & $\mathbf{W}_{\mathbf{c}}(\mathbf{m m})$ & $\mathbf{t}_{\mathbf{1}}(\mathbf{m m})$ & $\mathbf{H}_{-} \mathbf{t}_{\mathbf{3}}(\mathbf{m m})$ & $\mathbf{H}_{\mathbf{f 1}}$ to $\mathbf{H}_{\mathbf{f} 6}(\mathbf{m m})$ & $\mathbf{D}_{\mathbf{f 1}}$ to $\mathbf{D}_{\mathbf{f} \mathbf{f}}(\mathbf{m m})$ \\
\hline 0.48 & 0.06 & 0.02 & 0.21 & 0.16 & 0.04 \\
\hline
\end{tabular}

Table 4: Grid refinement test results

\begin{tabular}{|c|c|c|}
\hline Number of cells & $\Delta T(K)$ & $\left|\frac{(\Delta T)_{i}-(\Delta T)_{i-1} \mid}{(\Delta T)_{i}}\right|$ \\
\hline 270180 & 14.8490 & - \\
341594 & 15.1358 & 0.0189 \\
432154 & 15.5244 & 0.0250 \\
582686 & 15.6441 & 0.0077 \\
\hline
\end{tabular}




\section{Goal-Driven Optimisation (GDO)}

The GDO tool is one of the tools under the ANSYS Design Exploration tool [20] whose main aim is to identify the relationship between the performance of a product and the design variables. It uses the response surface methodology (RSM) for its optimisation process. The RSM uses a group of mathematical and statistical techniques to develop an adequate functional relationship between a response of interest and a number of input variables, which are explained further in literature with Equations [25, 26].

Once a model is created and parameters defined, a response surface is created. Based on the number of input parameters, a given number of solutions (design points) is required to build this response surface (an approximation of the response of the system). After inserting a response surface, the design space is defined by giving the minimum and maximum values to be considered for each input variable. The design of experiments (DOE) part of the response surface system creates the design space sampling and when updated, a response surface is created for each output parameter.

The GDO is an optimisation technique that finds design candidates from the response surfaces. The objective is set in the GDO and then the optimisation problem is solved. The accuracy of the response surface for the design candidates is checked by converting it to a design point, and thereafter, a full simulation is performed for that point to check the validity of the output parameters [21].

Numerical simulations and optimisation were carried out for a fixed total volume $\mathrm{V}$ of 0.7 , 0.8 and $0.9 \mathrm{~mm}^{3}$ with fixed length $N$ of $10 \mathrm{~mm}$. The temperature of water pumped across the micro-channel was $20^{\circ} \mathrm{C}$ and heat flux applied to the bottom wall was $1 \times 10^{6} \mathrm{~W} / \mathrm{m}^{2}$. The design space for the response surface was defined as $54 \leq \mathrm{W}_{\mathrm{c}} \leq 66 \mu \mathrm{m}, 19 \leq \mathrm{t}_{1} \leq 29 \mu \mathrm{m}, 50 \leq$ $\mathrm{M}-\mathrm{t}_{3} \leq 60 \mu \mathrm{m}$ and $500 \leq \mathrm{H}_{\mathrm{c}} \leq 790 \mu \mathrm{m}$. The optimised design point chosen was required to meet the manufacturing constraints. The range of Bejan numbers used throughout the 
simulations was between $6.5 \times 10^{7}$ and $3.9 \times 10^{8}$ corresponding to a pressure drop of between 10 to $60 \mathrm{kPa}$. The range of solid volume fractions used in the present simulations based on the set design space was $0.42<\phi<0.70$. In the GDO, the objective function was to minimise the peak temperature based on the design space.

For the micro pin fins, the design space for the response surface (while taking into consideration the manufacturing constraints) was defined as $30 \leq \mathrm{H}_{\mathrm{f}} \leq 160 \mu \mathrm{m}$ and $40 \leq \mathrm{D}_{\mathrm{f}} \leq$ $60 \mu \mathrm{m}$. The fin spacing $s$ was fixed at $62.5 \mu \mathrm{m}$ with the micro pin fins modelled as arranged at the centre of the microchannel.

For the variable axial length, the range of length used was $6 \leq \mathrm{N} \leq 10 \mathrm{~mm}$ while the design space for the micro pin fins was defined as $70 \leq D_{f} \leq 95 \mu \mathrm{m}$ for the pin-fin diameter and $41 \leq$ $\mathrm{H}_{\mathrm{f}} \leq 280 \mu \mathrm{m}$ for the pin-fin height.

\section{Results and discussion}

Table 5 shows a comparison between the results obtained by Bello-Ochende et al. [13] and the results of the present study for different solid volumes at a constant Bejan number.

Table 5: Optimal design results for $B e=3.2 \times 10^{8}$

\begin{tabular}{|c|c|c|c|c|c|}
\hline & $\begin{array}{c}\text { Volume } \\
(\mathbf{m m 3})\end{array}$ & $\begin{array}{c}\text { Minimised } \\
\text { Peak } \\
\text { Temperature } \\
\left({ }^{\circ} \mathrm{C}\right)\end{array}$ & $\begin{array}{c}\text { Optimised } \\
\text { Aspect Ratio } \\
\left(\frac{H_{c}}{W_{c}}\right)_{o p t}\end{array}$ & $\begin{array}{c}\text { Optimised } \\
\text { Volume } \\
\text { Fraction } \\
\phi_{\text {opt }}\end{array}$ & $\begin{array}{c}\text { Optimised } \\
\text { Channel } \\
\text { Hydraulic } \\
\text { Diameter } \\
\left(D_{h}\right)_{\text {opt }}\end{array}$ \\
\hline $\begin{array}{c}\text { Bello- } \\
\text { Ochende } e t \\
a l[13]\end{array}$ & 0.9 & 29.53 & 11.752 & 0.425 & 0.122 \\
\hline Present study & 0.9 & 29.52 & 12.228 & 0.475 & 0.115 \\
\hline $\begin{array}{c}\text { Bello- } \\
\text { Ochende } e t \\
a l[13]\end{array}$ & 0.8 & 29.79 & 10.069 & 0.425 & 0.123 \\
\hline Present study & 0.8 & 29.63 & 10.786 & 0.537 & 0.114 \\
\hline $\begin{array}{c}\text { Bello- } \\
\text { Ochende } e t \\
a l[13]\end{array}$ & 0.7 & 30.12 & 10.359 & 0.386 & 0.118 \\
\hline Present study & 0.7 & 29.75 & 8.887 & 0.573 & 0.118 \\
\hline
\end{tabular}


For a total solid volume of $0.9 \mathrm{~mm}^{3}$, Figure 4 shows a comparison between the numerical investigation of Bello-Ochende et al. [13] and this present work for the optimal peak wall temperature difference for different Bejan numbers. The figure shows that the values obtained in the present study were in good agreement with those of the previous work done with an average deviation of about $5.8 \%$.

In Figure 5, the influence of the dimensionless pressure drop on the maximised thermal conductance $\left(\mathrm{C}_{\max }\right)$ is reported. It is observed that the global thermal conductance increases with an increase in the dimensionless pressure drop, which is similar to what is reported in literature [13]. We also observe that as the solid volume is reduced, $\mathrm{C}_{\max }$ also reduces. From Figure 6 , we observe that the minimised peak temperature is inversely proportional to the maximum global thermal conductance $C_{\max }$. This shows that minimising the peak temperature maximises the global thermal conductance. Also, as the solid volume is reduced, the minimised peak temperature increases.

Figure 7 shows that the optimal channel aspect ratio $\left(\mathrm{H}_{\mathrm{c}} / \mathrm{W}_{\mathrm{c}}\right)_{\mathrm{opt}}$ was a constant value of 12.228, the solid volume fraction $\phi_{\text {opt }}$ was 0.475 and the channel hydraulic diameter $\left(D_{h}\right)_{\text {opt }}$ was $0.115 \mathrm{~mm}$ for different Bejan numbers for solid volume $V$ of $0.9 \mathrm{~mm}^{3}$ when the microchannel heat sink was optimised.

\subsection{Integrated design (ID) with fixed length}

Figure 8 shows results for the microchannel and integrated design with a fixed length of $10 \mathrm{~mm}$ for a solid volume $V$ of $0.9 \mathrm{~mm}^{3}$. It is observed that the peak temperature in the optimised microchannel was further minimised when three, four, five and six rows of micro pin fins were inserted in the optimised microchannel. The integrated design (ID) with three rows of micro pin-fin inserts gave the best result in minimising the peak temperature for all the ranges of $B e$ used in this study, which resulted in a $4 \%$ increase in the maximised thermal conductance for the lowest Bejan number.

Figure 9 shows a comparison between the maximum global thermal conductance for the optimised microchannel and the integrated design carried out in this study for a solid volume $V$ of $0.9 \mathrm{~mm}^{3}$. It is observed that there was an increase in $\mathrm{C}_{\max }$ when the micro pin fins were inserted in the microchannel but when the number of rows of pin fin becomes greater than three, the effect of inserting pin fins into the microchannel became insignificant. 
The optimal micro pin-fin aspect ratio $\left(\frac{H_{f}}{D_{f}}\right)_{o p t}$ for six rows of micro pin-fin inserts for a solid volume $V$ of $0.9 \mathrm{~mm}^{3}$ was 0.751 . When the volume constraint was applied with fixed fin heights, the optimal micro pin-fin aspect ratio for three, four and five rows of micro pin-fin inserts had a constant value of $0.531,0.614$ and 0.686 respectively for the whole range of Bejan numbers used in this study. The pin-fin aspect ratio for two rows of micro pin fins was 0.434, which did not meet the manufacturing constraint in Equation (6). Therefore, numerical simulations for this were not reported.

\subsection{Integrated Design(ID) with variable axial length}

Figures 10 and 11 show a comparison between results obtained for the minimised peak temperature and maximised thermal conductance for the fixed and variable length for a solid volume $V$ of $0.9 \mathrm{~mm}^{3}$. These results show that for the lowest $B e$ of $6.5 \times 10^{7}$ (pressure drop of $10 \mathrm{kPa}$ ), the peak temperature was further minimised by $39.8 \%$, which resulted in over $100 \%$ improvement in the maximum thermal conductance. It is observed that as the axial length was increased, the minimised peak temperature increased as shown in Figure 12. Figure 13 shows that the optimal length for the range of $B e$ used in this study was $6 \mathrm{~mm}$. Figure 14 shows that the optimal channel aspect ratio $\left(\mathrm{H}_{\mathrm{c}} / \mathrm{W}_{\mathrm{c}}\right)_{\mathrm{opt}}$ was 9.202 , solid volume fraction $\phi_{\mathrm{opt}}$ was 0.440 and channel hydraulic diameter $\left(D_{h}\right)_{\text {opt }}$ was $0.172 \mathrm{~mm}$ for different Bejan numbers and optimal axial length.

Figures 15 and 16 show the results for the integrated design with four to seven rows of micro pin-fin inserts for minimised peak temperature and maximised thermal conductance for $\mathrm{V}$ of $0.9 \mathrm{~mm}^{3}$. From these results, it is observed that six rows of micro pin-fin inserts gave the best results with an optimal pin-fin aspect ratio $\left(\frac{H_{f}}{D_{f}}\right)_{o p t}$ of 0.68 , which resulted in about $5 \%$ increase in the maximised thermal conductance for the lowest Bejan number. When the volume constraint was applied, the optimal micro pin-fin aspect ratio for four, five and seven rows of micro pin fins had a constant value of $0.555,0.621$ and 0.735 respectively for the whole range of Bejan numbers used in this study. The pin-fin aspect ratio for the integrated design with three rows was 0.480 , which did not meet the manufacturing constraint as stated in Equation (6). As a result of this, numerical simulation results for this were not reported for the variable axial length. 


\section{Conclusion}

In this study, three-dimensional numerical investigations were carried out to optimise the geometric parameters of a microchannel heat sink for constant solid volumes with micro pinfin inserts. Results from this integrated design were compared with those obtained for microchannels without the pin fins for both fixed and relaxed lengths. For a fixed length, observations made in this study can be summarized as follows:

Increasing the Bejan number further minimised the peak temperature of the microchannel which is also reflected in the increased maximum global thermal conductance.

The integrated design with three to six rows of micro pin-fin inserts further minimised the peak temperature of the microchannel, which resulted in a further increase in the maximum global thermal conductance. These results show that microchannels with a few rows of short micro pin fins give better results than microchannels without the pin fins. For a solid volume of $0.9 \mathrm{~mm}^{3}$, the integrated design with rows of micro pin fins greater than three did not improve the minimisation of the peak temperature.

When the axial length of the microchannel heat sink was relaxed, the maximum thermal conductance was improved by over $100 \%$ for a solid volume of $0.9 \mathrm{~mm}^{3}$ for the lowest Bejan number used in this study. The integrated design further improved the results for the minimised peak temperature and the maximised thermal conductance. For the solid volume of $0.9 \mathrm{~mm}^{3}$, the integrated design with six rows of micro pin-fin inserts gave the best results for the whole range of Bejan numbers used in this study.

From the numerical investigations carried out in this study, the microchannel heat sink and integrated design with uniform pin fins performed best when the length was relaxed for all solid volumes used in this study. Also for both fixed and relaxed lengths, the integrated design gave the best result for minimisation of peak temperature and maximisation of thermal conductance.

\section{Acknowledgements}

The funding obtained from the NRF, TESP, University of Stellenbosch, University of Pretoria, SANERI/SANEDI, CSIR, EEDSM Hub and NAC is acknowledged and duly appreciated. 


\section{References}

[1] D.B. Tuckerman and R.F.W. Pease, High Performance Heat Sinking for VLSI, IEEE Electronic Device Letters EDL-2 (1981) 126-129.

[2] R.W. Knight, D.J. Hall, J.S. Goodling, R.C. Jaeger, Heat Sink Optimization with Application to Micro-channels, IEEE Transactions of Components, Hybrids and Manufacturing Technology 15 (1992) 832-842.

[3] C. Perret, J. Boussey, C. Schaeffer, M. Coyaud, Analytical Modeling, Optimization and Realization of Cooling Devices in Silicon Technology, IEEE Transactions on Components and Packaging Technologies 23 (2000) 665-672.

[4] Y. Murakami, B.B. Mikic, Parametric Optimization of Multi-channeled Heat Sinks for VLSI Chip Cooling, IEEE Transactions on Components and Packaging Technologies 24 (2001) 2-9.

[5] H.R. Upadhye, S.G. Kandlikar, Optimization of Micro-channel Geometry for Direct Chip Cooling Using Single Phase Heat Transfer, ASME Conference on Micro-channels and Mini-channels (2004) Rochester, New York, USA.

[6] J.H. Ryu, D.H. Choi, S.J. Kim, Numerical optimization of the thermal performance of a micro-channel heat sink, International Journal of Heat and Mass Transfer 45 (2002) 28232827.

[7] J.H. Ryu, D.H. Choi, S.J. Kim, Three-dimensional numerical optimization of a manifold micro-channel heat sink, International Journal of Heat and Mass Transfer 46 (2003) 15531562.

[8] N. Muller, L.G. Frechette, Optimization and Design Guidelines for High Flux MicroChannel Heat Sinks for Liquid and Gaseous Single-Phase Flow, Inter Society Conference on Thermal Phenomena (2002) 449-456.

[9] J. Li, G.P. Peterson, Geometric Optimization of a Micro Heat Sink with Liquid Flow, IEEE Transactions on Component and Packaging Technologies 29 (2006) 145-154.

[10] J. Li, G.P. Peterson, 3-Dimensional numerical optimization of silicon-based high performance parallel micro-channel heat sink with liquid flow, International Journal of Heat and Mass Transfer 50 (2007) 2895-2904.

[11] S. Ndao, Y. Peles, M.K. Jensen, Multi-objective thermal design optimization and comparative analysis of electronics cooling technologies, International Journal of Heat and Mass Transfer 52 (2009) 4317-4326. 
[12] A. Husain, K. Kim, Shape Optimization of Micro-Channel Heat Sink for MicroElectronic Cooling, IEEE Transactions on Components and Packaging Technologies 31 (2008) 322-330

[13] T. Bello-Ochende, J.P. Meyer, F.U. Ighalo, Combined numerical optimization and constructal theory for the design of micro-channel heat sinks, Numerical Heat Transfer, Part A 58 (2010) 882-899.

[14] F.U. Ighalo, Optimization of Micro-channels and Micro-pin-fin Heat Sinks with Computational Fluid Dynamics in Combination with a Mathematical Optimization Algorithm, M.Eng. Thesis (2010).

[15] A. Bejan, S. Lorente, The constructal law and the thermodynamics of flow systems with configuration, International Journal of Heat and Mass Transfer 47 (2004) 3203-3214.

[16] T. Bello-Ochende, L. Liebenberg, J.P. Meyer, Constructal cooling channels for microchannel heat sinks, International Journal of Heat and Mass Transfer 50 (2007) 4141-4150.

[17] T. Bello-Ochende, J.P. Meyer, A. Bejan, Constructal multi-scale pin-fins, International Journal of Heat and Mass Transfer 53 (2010) 2773-2779.

[18] M. Almogbel, A. Bejan, Cylindrical trees of pin fins, International Journal of Heat and Mass Transfer 43 (2000) 4285-4297.

[19] T. Bello-Ochende, J.P. Meyer, A. Bejan, Constructal ducts with wrinkled entrances, International Journal of Heat and Mass Transfer 52 (2009) 3628-3633.

[20] G.S. Bhattacharjee, W.L. Grosshandler, The formation of wall jet near a high temperature wall under microgravity environment, ASME HTD 96 (1988) 711-716.

[21] S. Petrescu, Comments on the optimal spacing of parallel plates cooled by forced convection, International Journal of Heat and Mass Transfer 37 (1994) 1283.

[22] ANSYS FLUENT 14.0 User's Guide Documentation, 2011.

[23] S.V. Pantakar, Numerical Heat Transfer and Fluid Flow, Hemisphere Publishing Corp., 1980.

[24] W.A. Khan, J.R. Culham, M.M. Yovanovich, Performance of shrouded pin-fin heat sinks for electronic cooling, Journal of Thermophysics and Heat Transfer 20 (2006) 408414.

[25] A.I. Khuri, S. Mukhopadhyay, Response surface methodology, Advanced Review 2 (2010) 128-149.

[26] R.H. Myers, D.C. Montgomery, Response surface methodology: Process and product optimization using designed experiments, Wiley, New York, 2002. 


\section{List of Figures}

Figure 1 (a) Physical model of a microchannel heat sink

Figure 2 (a) Cross-section of a micro pin fin inserted in a microchannel (b) 3D Computational domain

Figure 3 Validation of code for thermal resistance versus (a) pin diameter (b) pin height

Figure 4 Influence of dimensionless pressure drop on optimal peak wall temperature difference for total heat sink volume of $0.9 \mathrm{~mm}^{3}$

Figure 5 Influence of dimensionless pressure drop on the maximised thermal conductance

Figure 6 Influence of dimensionless pressure drop on minimised peak wall temperature

Figure 7 Effect of the change in $B e$ on optimal channel aspect ratio, solid volume fraction and hydraulic diameter

Figure 8 Minimised peak temperature for microchannel and the integrated design at fixed total solid volume $V$ of $0.9 \mathrm{~mm}^{3}$

Figure 9 Maximised thermal conductance for microchannel and the integrated design at fixed total solid volume $V$ of $0.9 \mathrm{~mm}^{3}$

Figure 10 Comparison between results of minimised peak temperature for fixed and relaxed lengths

Figure 11 Comparison between results of maximised thermal conductance for fixed and relaxed lengths

Figure 12 Effect of variable axial length on minimised peak temperature for a constant $B e$

Figure 13 Optimal lengths for each Bejan number

Figure 14 Effect of the change in Be on optimal channel aspect ratio, solid volume fraction and hydraulic diameter for optimal axial length

Figure 15 Minimised peak temperatures for microchannel and integrated design at fixed total solid volume $V$ of $0.9 \mathrm{~mm}^{3}$ when length is relaxed

Figure 16 Maximised thermal conductance for microchannel and integrated design at fixed total solid volume $V$ of $0.9 \mathrm{~mm}^{3}$ when length is relaxed 


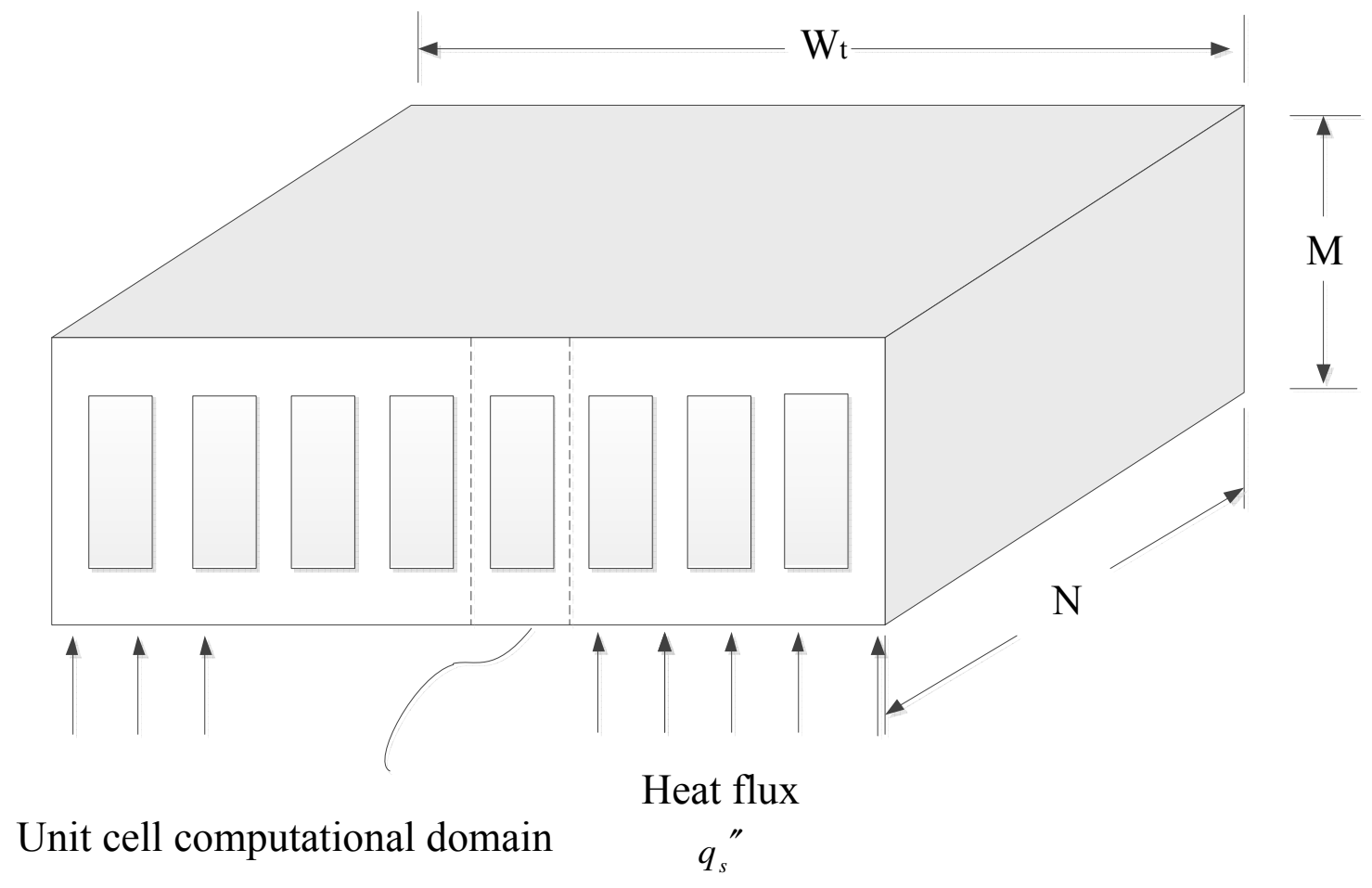

Figure 1 


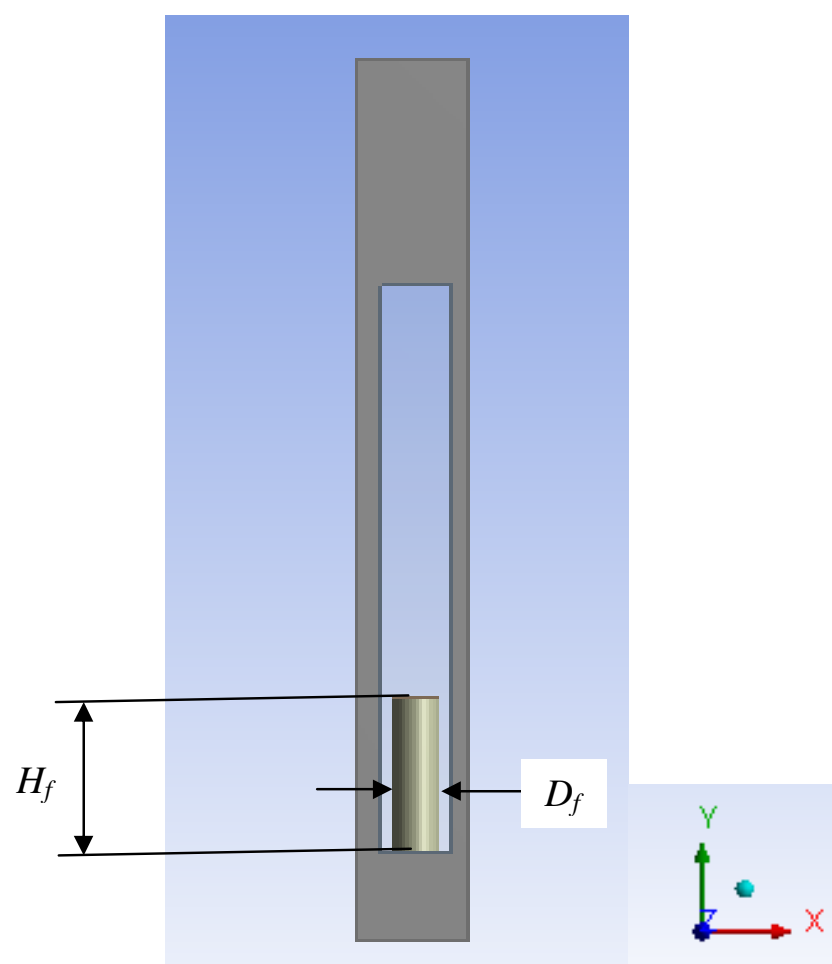

(a)

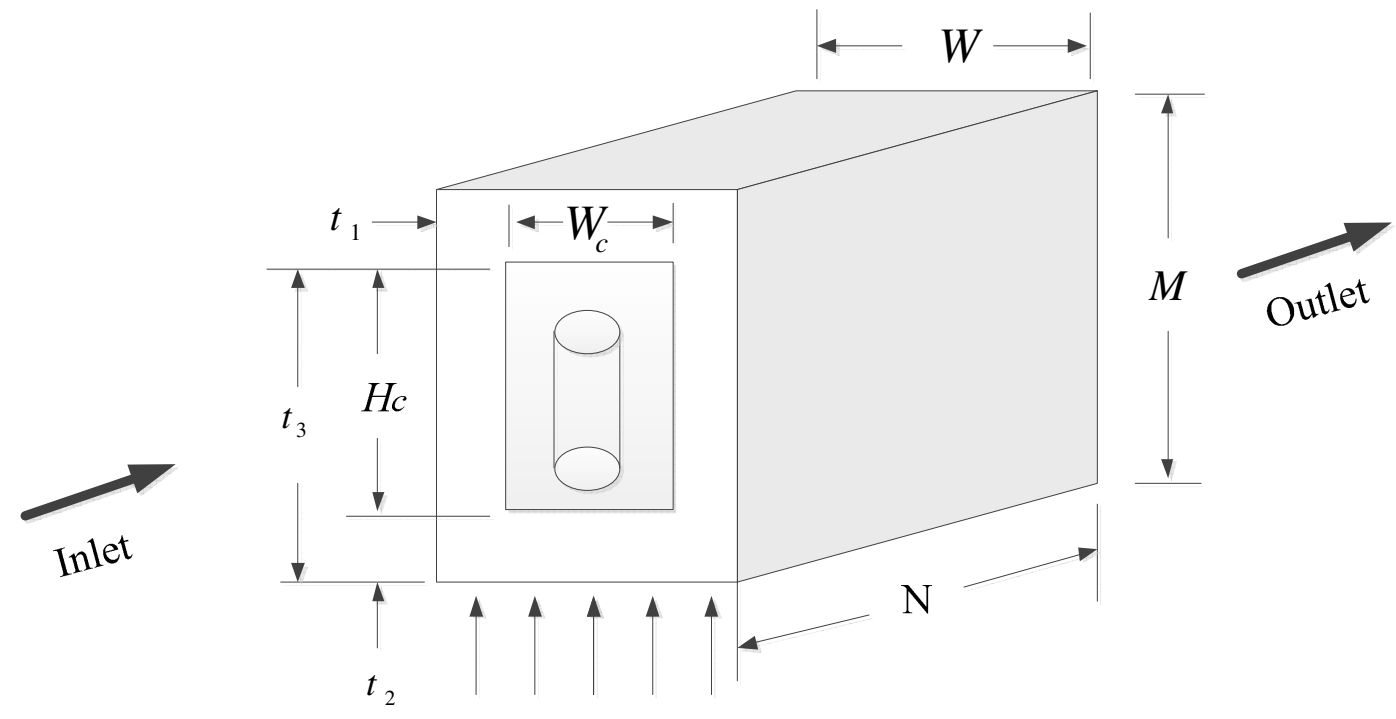

(b)

Figure 2 


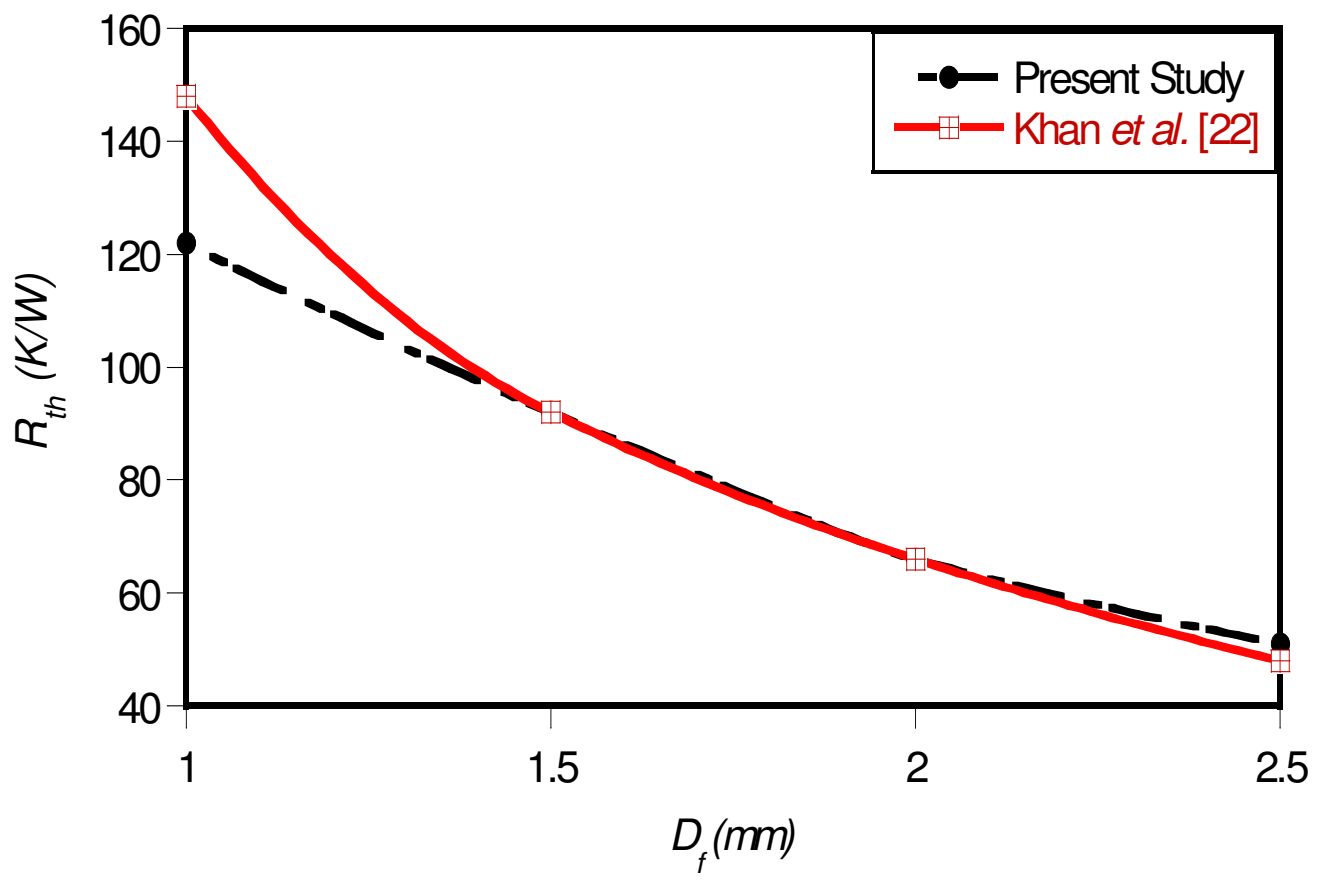

(a)

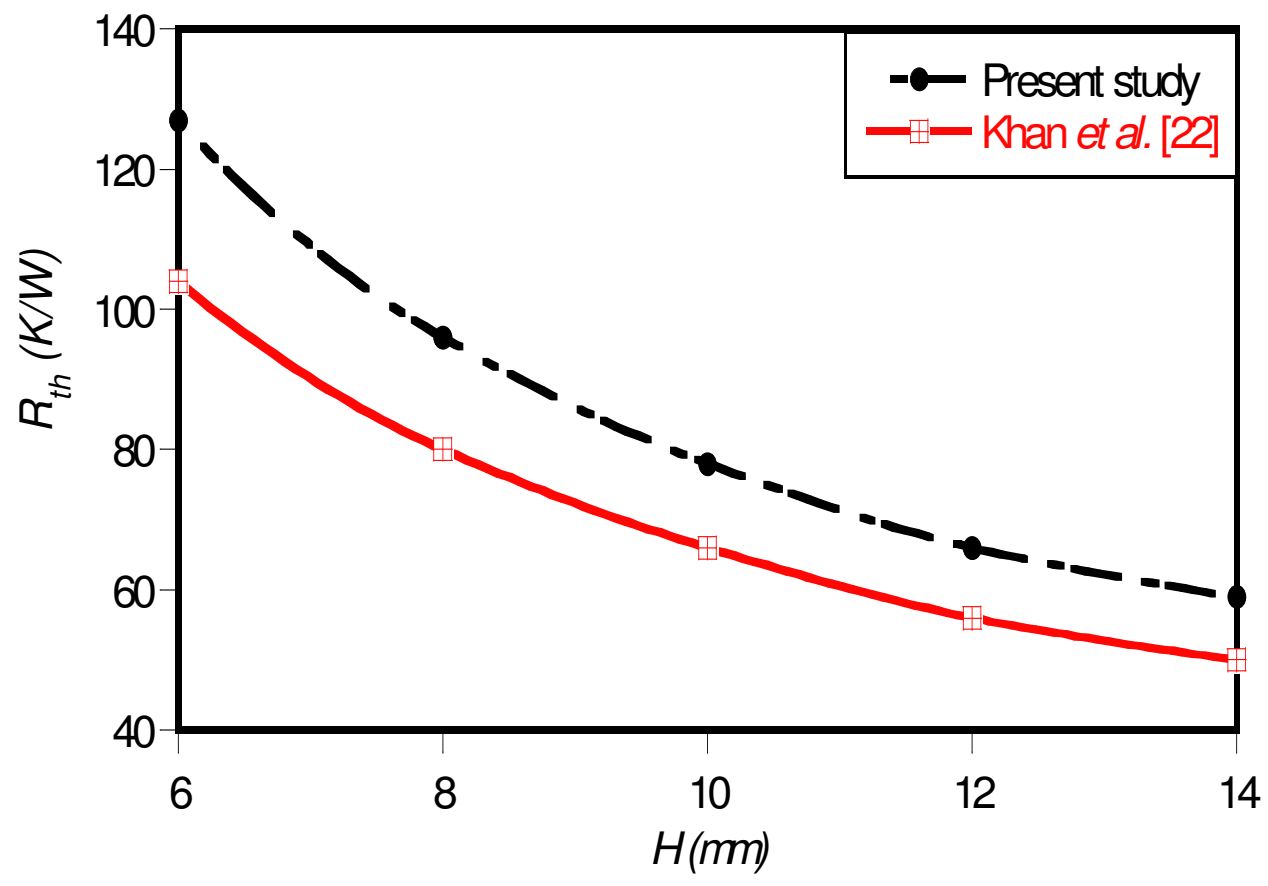

(b)

Figure 3 


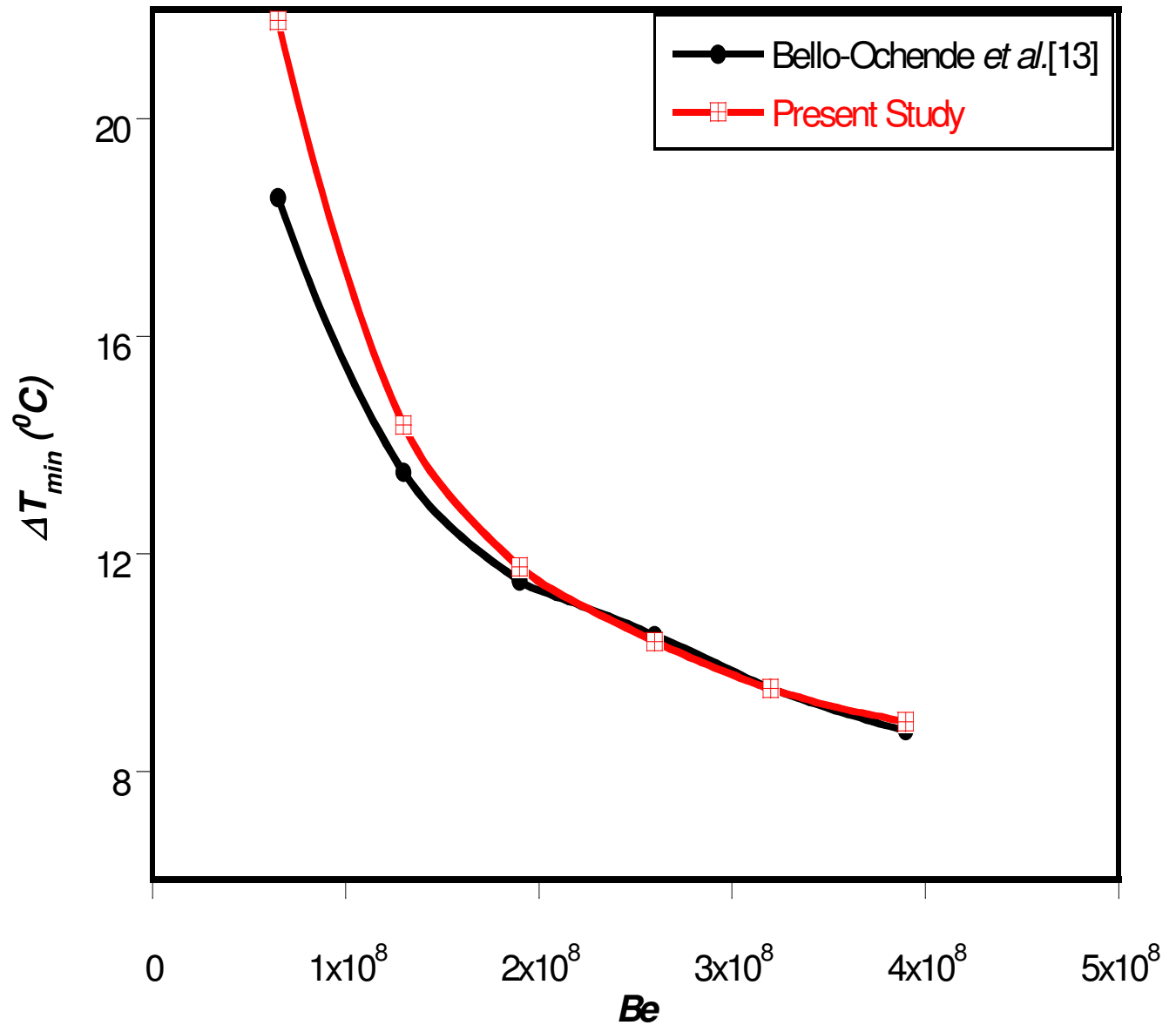

Figure 4 


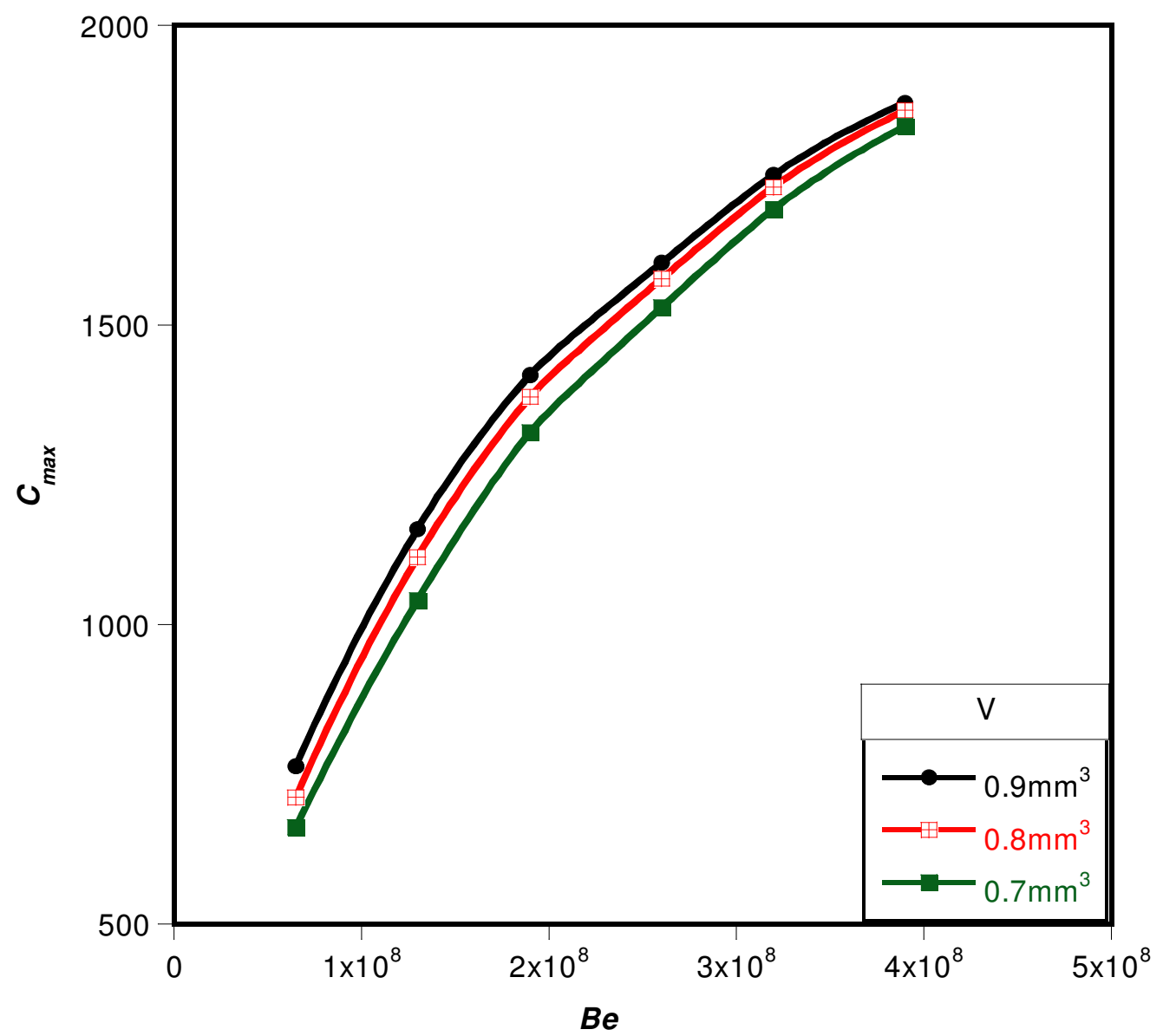

Figure 5 


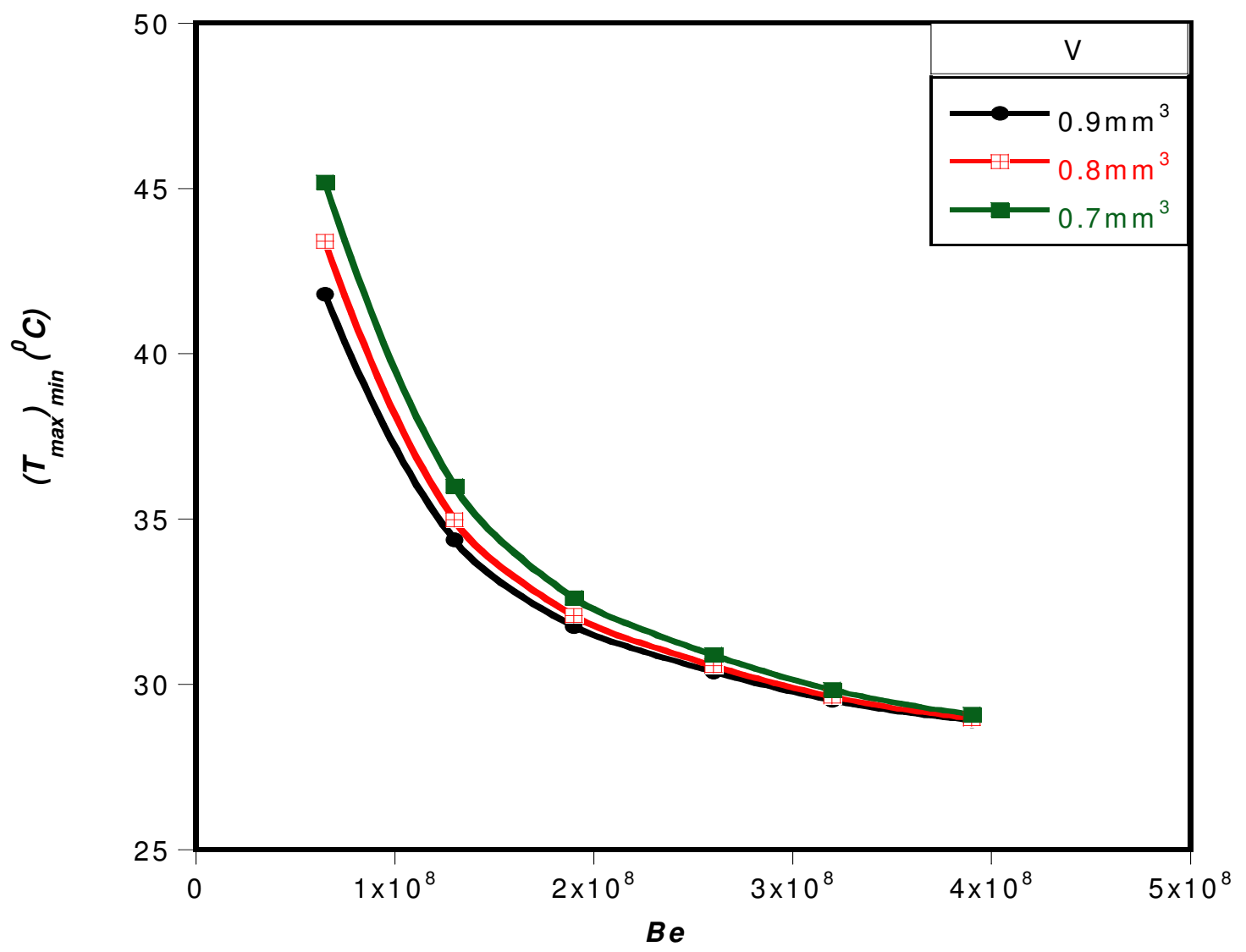

Figure 6 


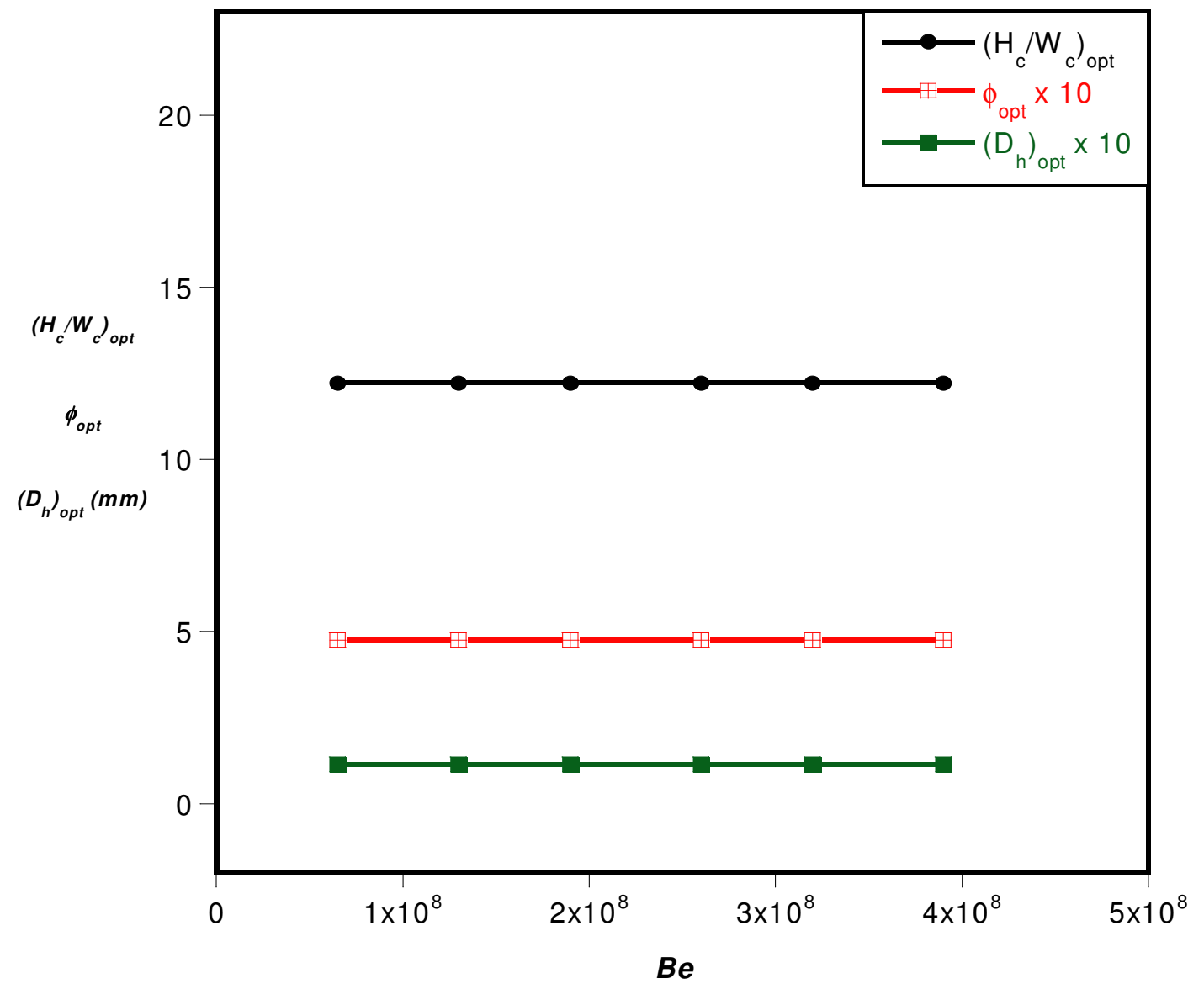

Figure 7 


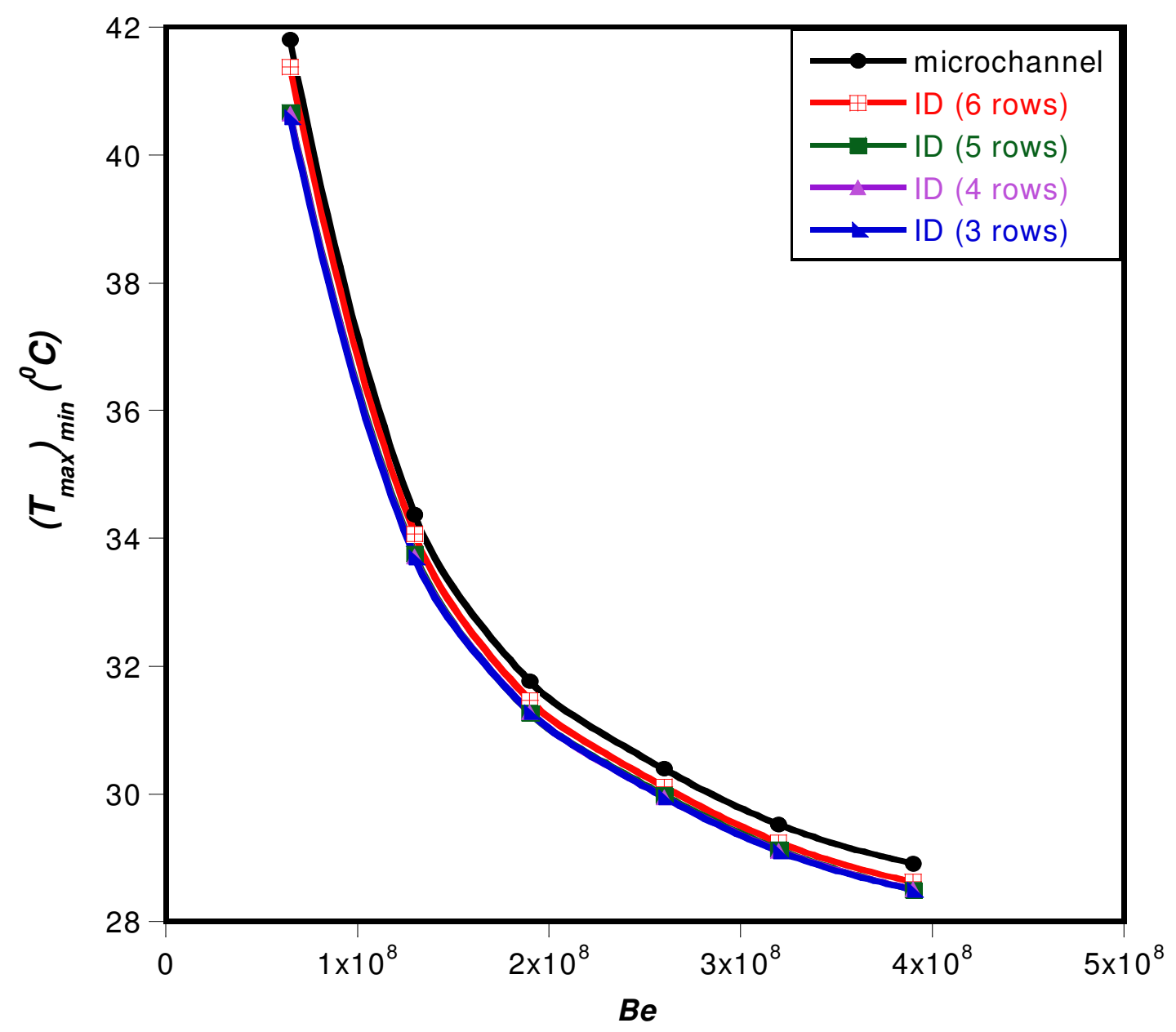

Figure 8 


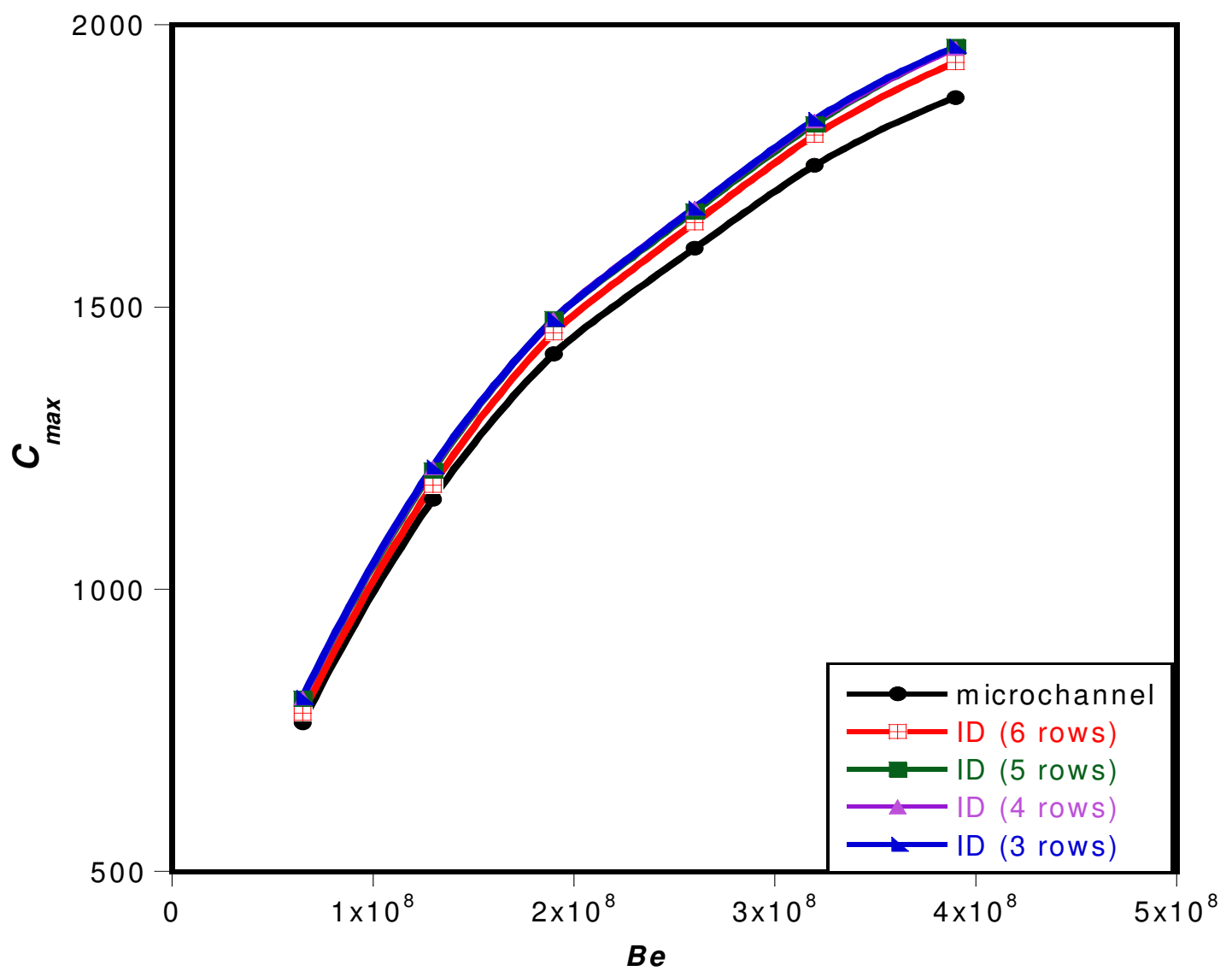

Figure 9 


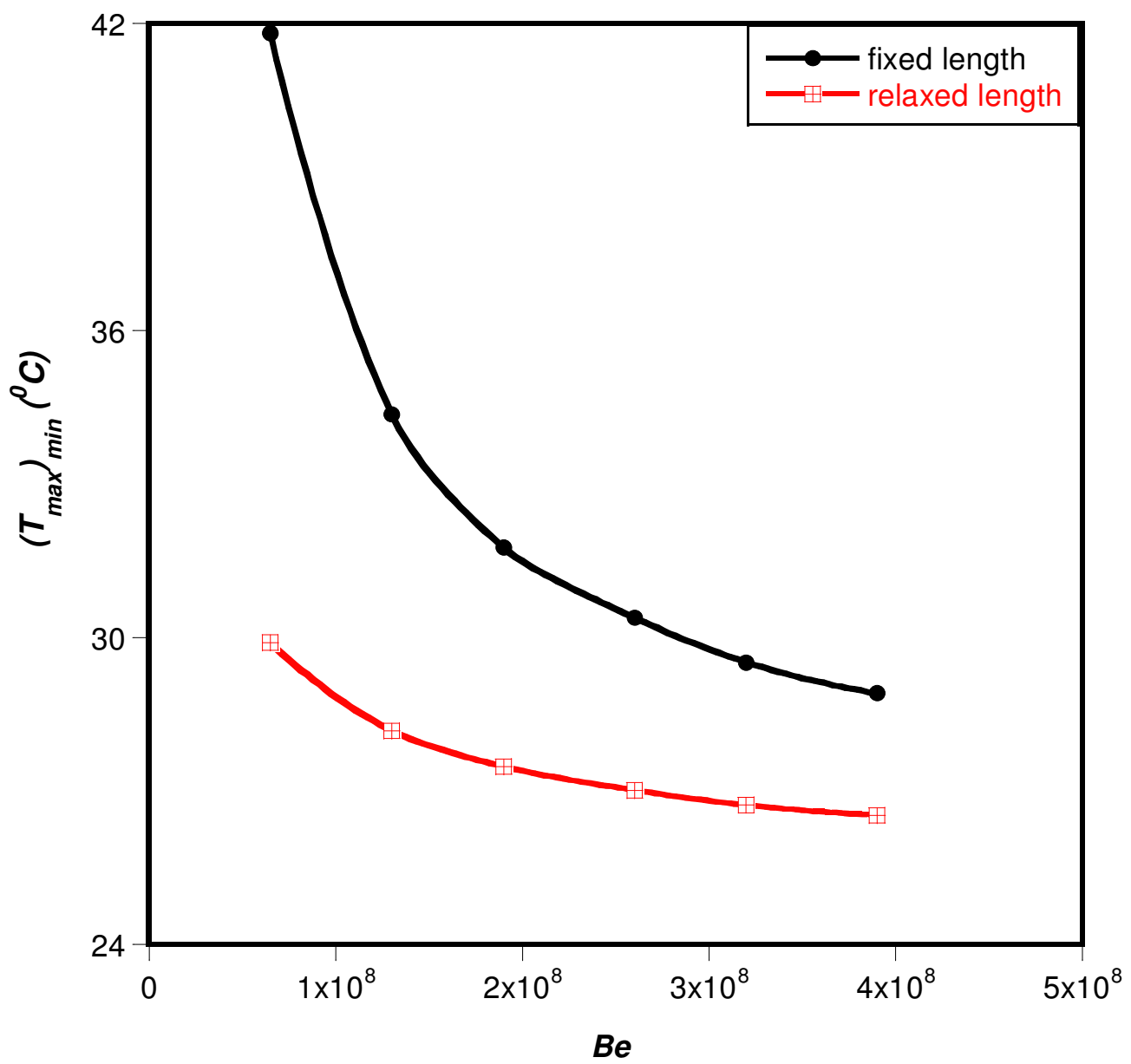

Figure 10 


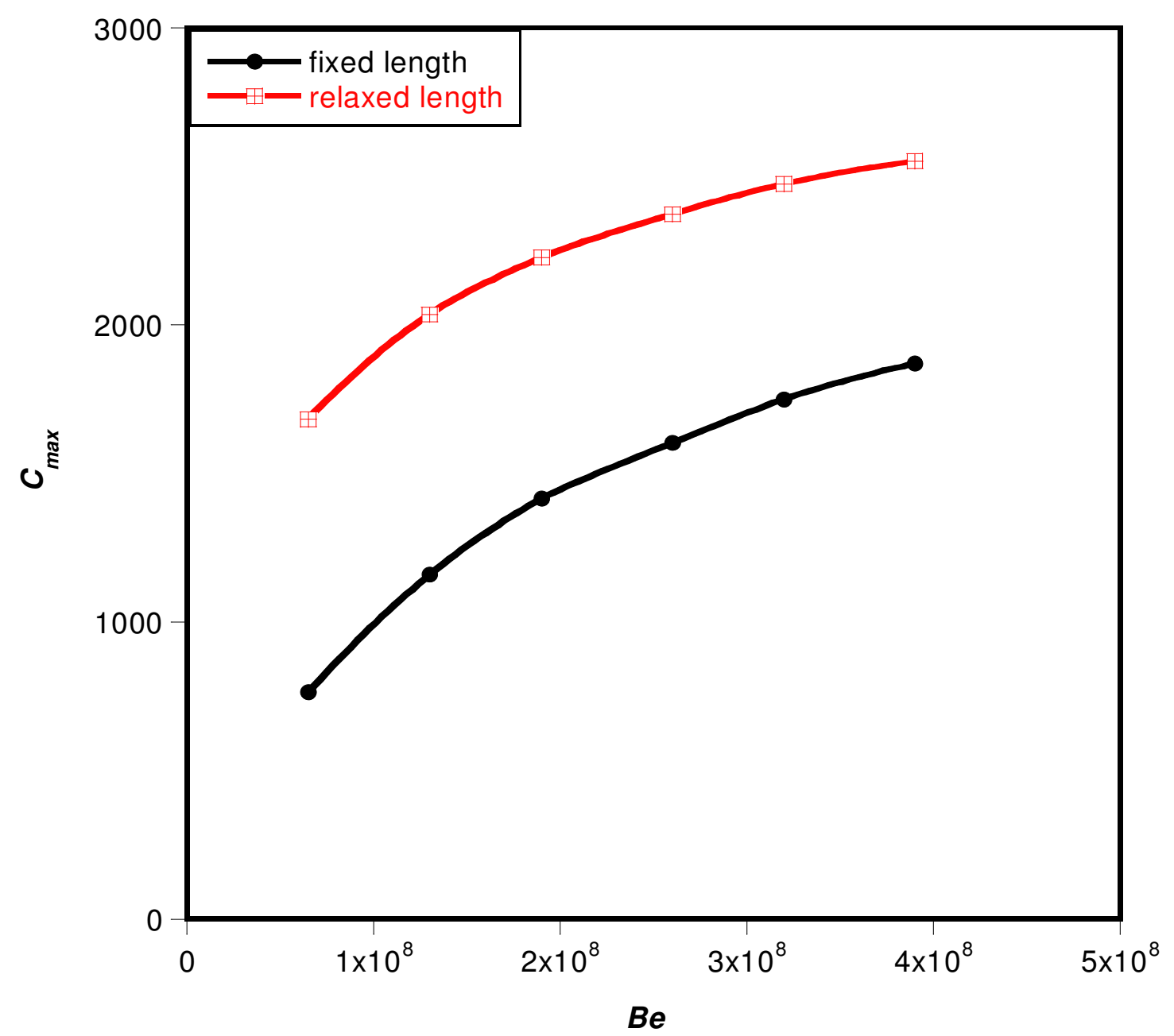

Figure 11 


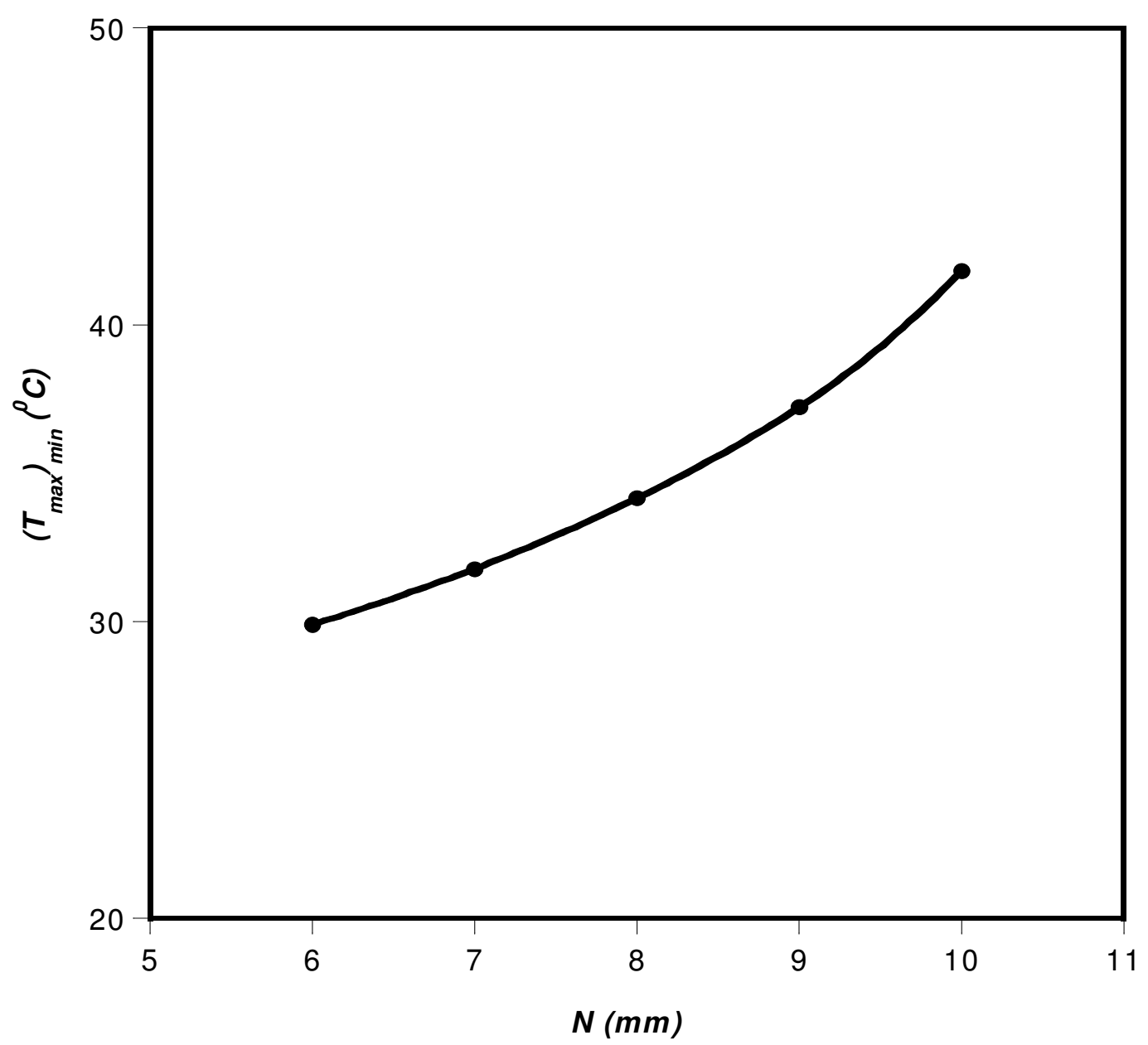

Figure 12 


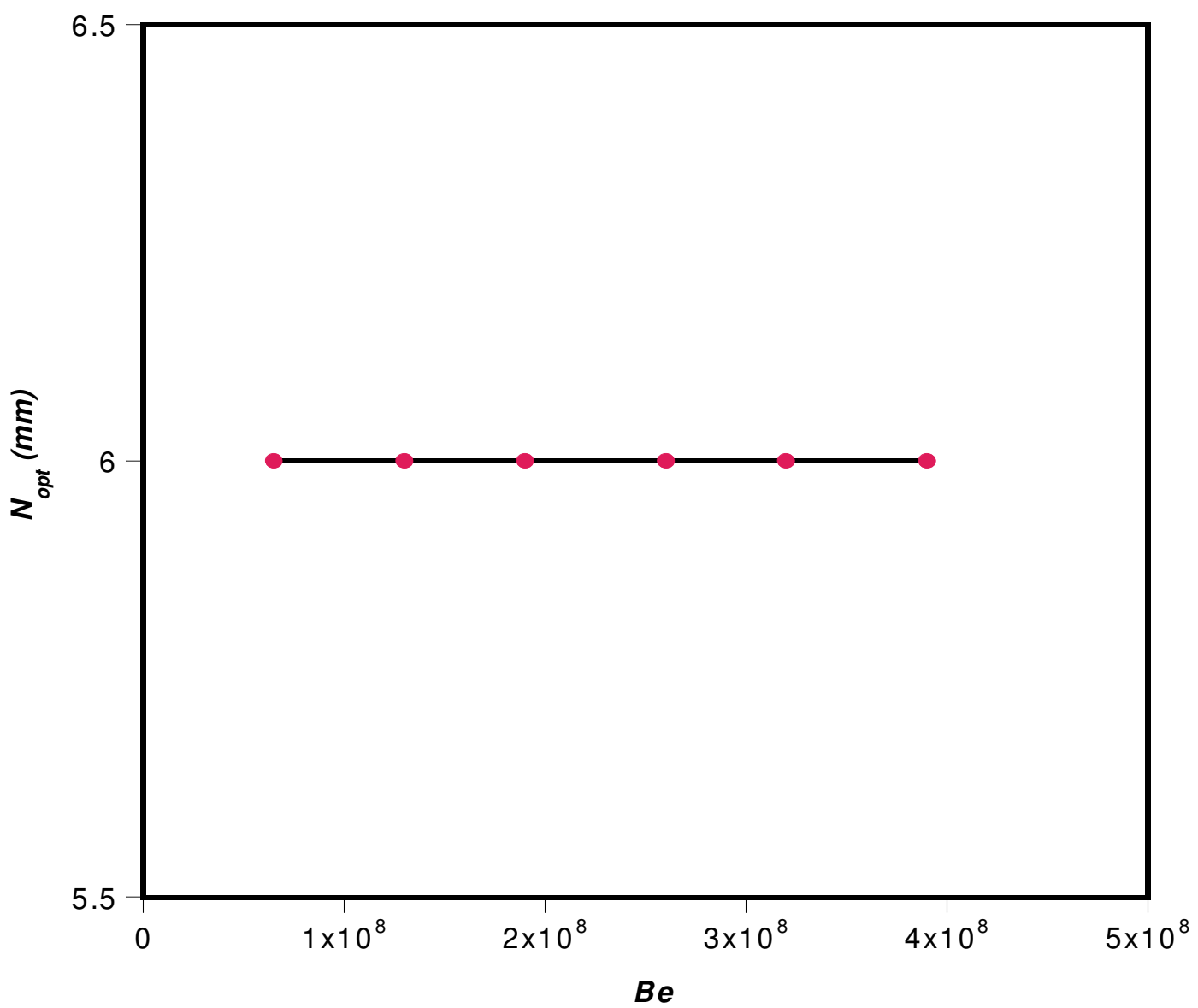

Figure 13 


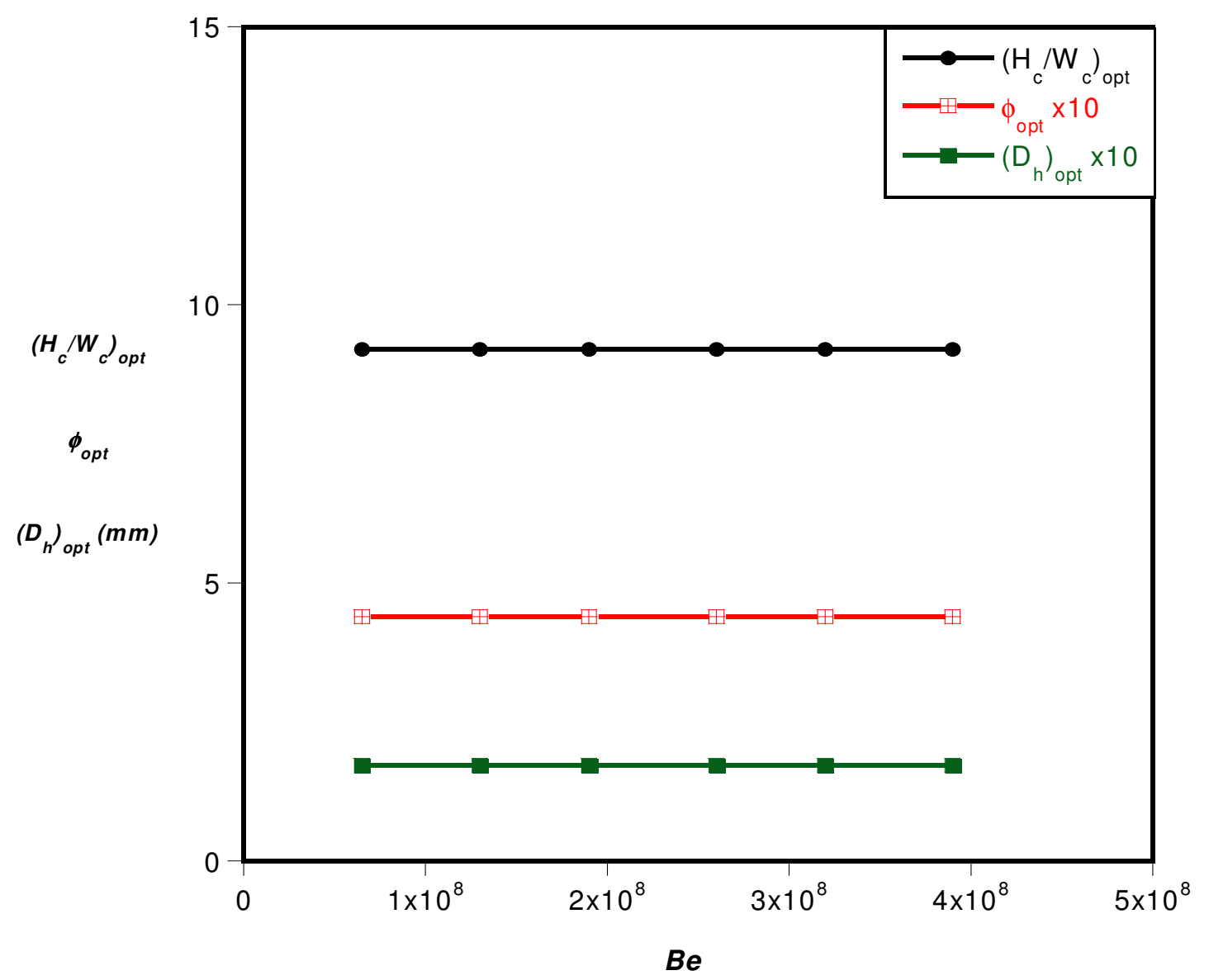

Figure 14 


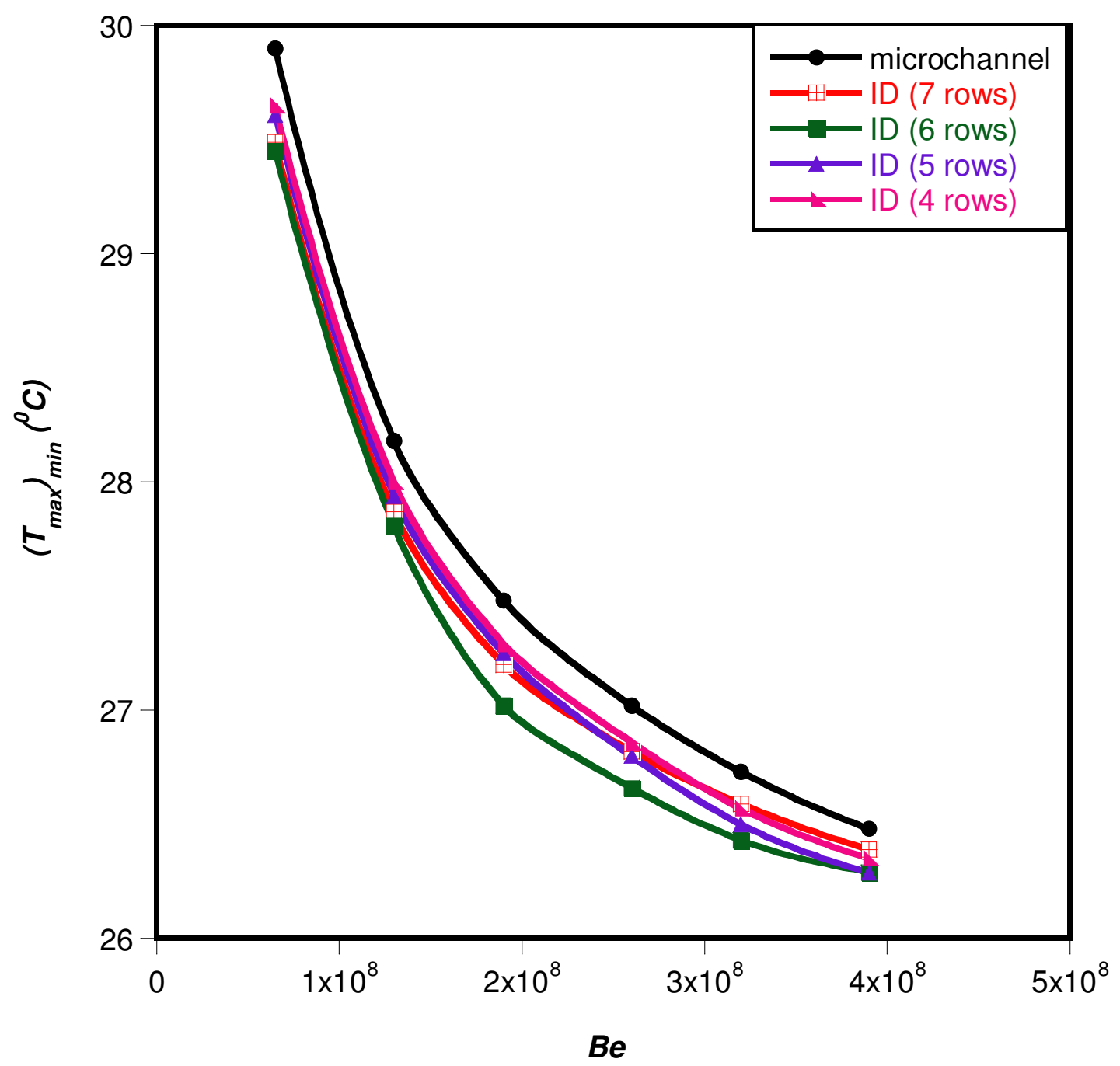

Figure 15 


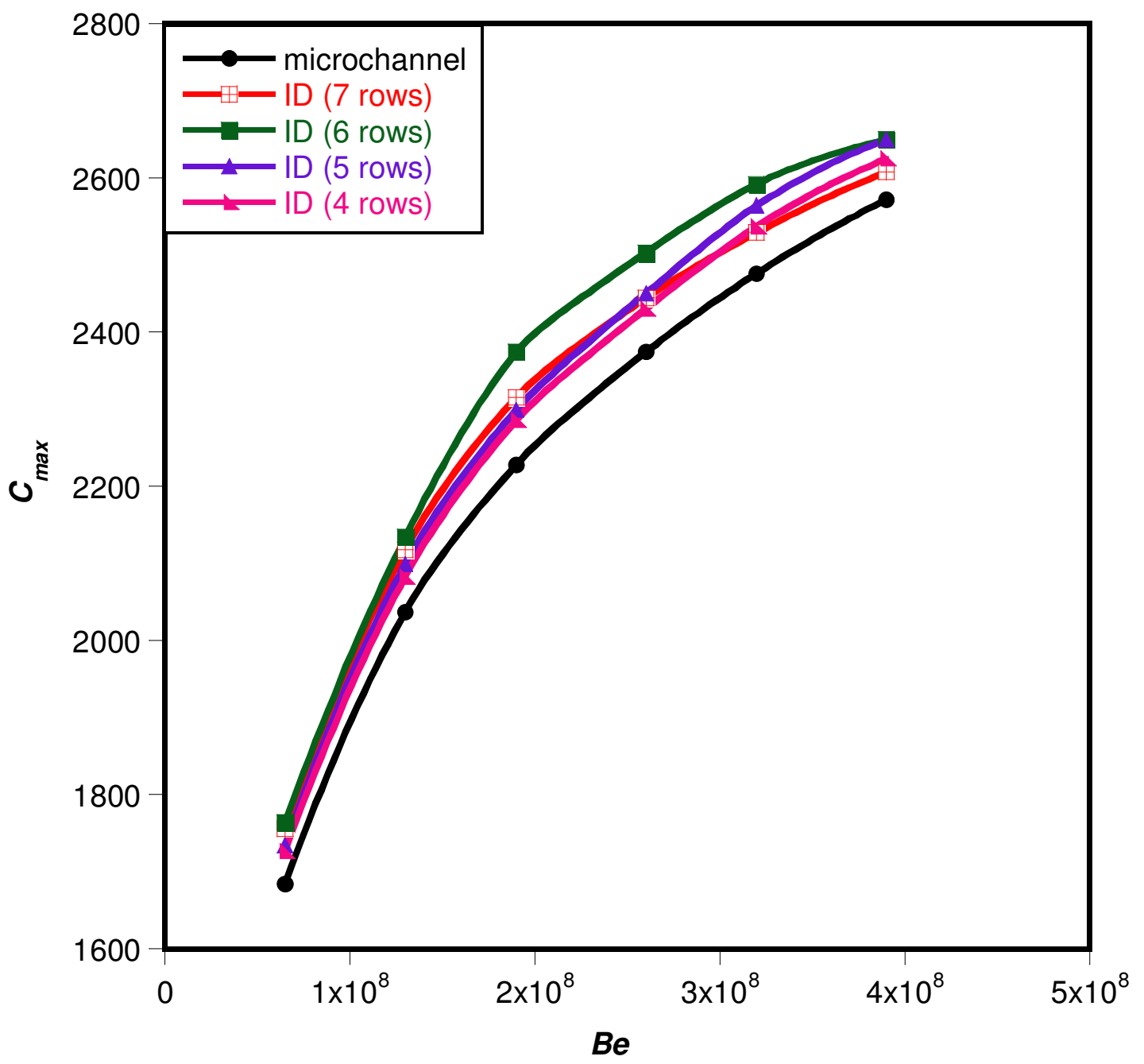

Figure 16 